\title{
The onset of fertility transition in Pakistan
}

Zeba Sathar

Population Council

John B. Casterline

Follow this and additional works at: https://knowledgecommons.popcouncil.org/departments_sbsr-pgy

Part of the Demography, Population, and Ecology Commons, Family, Life Course, and Society Commons, and the International Public Health Commons How does access to this work benefit you? Let us know!

\section{Recommended Citation}

Sathar, Zeba and John B. Casterline. 1998. "The onset of fertility transition in Pakistan," Policy Research Division Working Paper no. 112. New York: Population Council. Version of record: https://doi.org/ $10.2307 / 2808024$ 


\section{The 0 nset of Fertility Transition in Pakistan}

Zeba A. Sathar

John B. Casterline

1998 No. 112 


\title{
The Onset of Fertility Transition in Pakistan
}

\author{
Zeba A. Sathar \\ John B. Casterline
}

Zeba A. Sathar is Associate, Population Council, Islamabad, Pakistan. John B. Casterline is Senior Associate, Policy Research Division, Population Council. 


\begin{abstract}
Recent trends in fertility and contraceptive prevalence indicate that the marital fertility transition in Pakistan, which has been anticipated for three decades, has begun in the 1990s. Before that decade, the total fertility rate had exceeded six births per woman for at least three decades, and fewer than 10 percent of married women practiced contraception. The most recent survey data, collected in 1996-97, show a total fertility rate of 5.3 births per woman and a contraceptive prevalence rate of 24 percent. Underlying this development are macroeconomic trends that have led to widespread economic distress at the household level, and social changes that have diluted the influence of extended kin and resulted in greater husband-wife convergence in reproductive decisionmaking. The more-direct causes of declining fertility are a crystallization of existing desires for smaller families along with a decline in family size desires and a reduction in the social, cultural, and psychic costs of contraception. Improvements in family planning services (their density and quality) have contributed little to the onset of fertility decline but could be decisive in sustaining the decline over the next decade. Other obstacles to contraceptive use, including fear of health side effects and perceptions that husbands are opposed, must also be overcome in order for contraceptive practice to become more widespread and the decline in fertility to continue. Over the long term, progression to replacement-level fertility will require a substantial decline in the demand for children.
\end{abstract}

This material may not be reproduced in any form without written permission from the authors. 
Fertility in Pakistan has shown a stubborn resistance to change. Because of sharp declines in mortality in the post-World War II period, the population of Pakistan was growing at the rate of 2.7 percent per annum around 1960. In response to concern about rapid growth, a national policy of slowing population growth was articulated in the 1960 s, with a program of family planning services as the main tool (Government of Pakistan 1965). During its first two decades, however, the program appeared to have had scant impact on fertility: the total fertility rate (TFR) continued to hover between six and seven births per woman throughout the 1970s and 1980s, and the population growth rate approached 3 percent per annum (Sathar 1993). Repeated assertions that marital fertility decline was underway proved to be illusory. ${ }^{1}$

In this paper we present empirical evidence from multiple and independent studies carried out in the past eight years demonstrating that marital fertility decline has finally begun in Pakistan. The decline is gentle but nevertheless represents a genuine break from the past, most notably because of the increasing use of modern contraception for the purpose of limiting family size. The slight declines in overall fertility prior to 1990 were due almost entirely to increases in age at first marriage (United Nations 1993).

With a population of 130.5 million in 1998 (Population Census Organization 1998), Pakistan is the world's seventh most populous country. According to UN projections, it will become the third most populous by the year 2050. It is one of only eight countries as of the mid-1990s with a population in excess of 25 million in combination with a TFR in excess of five births per woman (UN 1996). Pakistan stands apart from its populous neighbors in South Asia, all of which (with the exception of Nepal) experienced substantial declines in fertility prior to 1990 and therefore show markedly lower fertility in the mid-1990s (estimated TFRs in 1995 are 2.2 for Sri Lanka, 3.4 for India and Bangladesh, and 5.4 for Nepal). ${ }^{2}$ These comparisons raise questions about which factors have precipitated and sustained fertility transition in the region, in particular the contribution of family planning programs (Shah and Cleland 1993). Some analysts credit the 
rapid and, by many criteria, early fertility decline in Bangladesh to the effectiveness of the family planning program (Cleland et al. 1994). Pakistan's program, by comparison, has repeatedly been criticized for poor management and the low quality of the services offered to the majority of its clients (Robinson et al. 1981; Rukanuddin and Hardee-Cleaveland 1992; United Nations n.d.). An alternative, and not necessarily contradictory, argument is that the motivation to limit fertility did not crystallize in Pakistan before the 1990s, and therefore responsibility for the late transition cannot be placed entirely on an indecisive population policy and inadequate family planning services (Sathar 1993).

This paper offers an update on fertility transition in Pakistan. We first review the evidence suggesting that important changes are underway. The paper next describes the large-scale social and economic changes that have motivated the recent changes in reproductive behavior. We then examine the more-direct causes of these changes and the constraints on further changes. We conclude by speculating about the prospects for further declines in fertility in Pakistan.

\section{STATUS OF THE FERTILITY TRANSITION}

Numerous fertility surveys indicate that the TFR remained above six births per woman throughout the 1980s (see Table 1). Significantly, all estimates for the 1990s for the first time fall below 6.0 births per woman. The direct estimate of the TFR for 1986-91 from the 1990-91 Pakistan Demographic and Health Survey (PDHS) is 5.4. This is almost certainly an underestimate, judging from the evidence from reinterviews conducted with a subsample of PDHS respondents. The reinterview data suggest that roughly 10 percent of births were omitted (Curtis and Arnold 1994). Adjusting for this through the Gompertz relational model, Juarez and Sathar (forthcoming) estimate that the TFR was probably around 6.1 for the period 1986-91, a figure that is consistent with the Pakistan Demographic Survey estimate for 1992 of 5.8 (Federal Bureau of Statistics 1997). The estimate 
$\underline{\text { Table } 1 \text { Trends in fertility in Pakistan: Total fertility rates, by decade and survey }}$

\begin{tabular}{llll} 
Decade and survey & $\begin{array}{c}\text { Period } \\
\text { covered }\end{array}$ & & \multicolumn{2}{c}{ TFR } \\
\cline { 2 - 4 } & Direct & Indirect \\
\hline
\end{tabular}

\section{0s}

Population Growth Estimation

Experiment (1962-65)

Pakistan Fertility Survey (1975)

National Impact Survey (1968-69)

1962-65

$8.0^{\mathrm{a}}$

1962-65 $\}$

$6.1^{\mathrm{a}}$

Population Growth Survey (1968-71)

1965-69

7.1

1968-69

5.0

1968-71

6.0

1970s

Pakistan Fertility Survey (1975)

1970-74

6.3

Pakistan Labour Force and Migration Survey (1979)

1970-74

7.1

Pakistan Labour Force and Migration Survey (1979)

1975-79

6.5

Population Growth Survey (1976-79)

1976-79

\section{0s}

Pakistan Contraceptive Prevalence

Survey (1984-85)

$\begin{array}{ll}1984-85 & 6.0 \\ 1984-88 & 6.9 \\ 1986-91 & 5.4\end{array}$

Survey (1990-91)

$1986-91$

5.4

Pakistan Demographic and Health

Survey (1990-91)

1987-91

$6.1^{\mathrm{b}}$

\section{0s}

Pakistan Demographic Survey (1992)

1992

5.8

Pakistan Contraceptive Prevalence

Survey (1994-95)

1994-95

Pakistan Fertility and Family Planning

Survey (1996-97)

1992-96

5.3

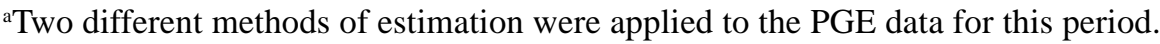

${ }^{\mathrm{b}}$ This rate was calculated by Juarez and Sathar (forthcoming) using the Gompertz relational model to adjust for misplacement errors and applies to $0-4$ years before the survey.

Sources: Sathar (1993): Table 1; Population Council (1998b): Table 7.6; NIPS/LSHTM (1998): Table 3.6. 
from the 1994-95 Pakistan Contraceptive Prevalence Survey (PCPS) is slightly lower yet at 5.6 for the period 1994-95 (Population Council 1998b). Collectively, these estimates imply a modest decline of 0.3 births during the four-year period 1991 through 1994, which if extrapolated implies a TFR of 5.4 in 1997. ${ }^{3}$ The Pakistan Fertility and Family Planning Survey (PFFPS) of 1996-97 (NIPS/ LSHTM 1998) provides a direct estimate of 5.3 for the period 1992-96, which suggests a slightly more rapid decline during the 1990s than implied by the previous surveys. ${ }^{4}$ Finally, the 1998 Census, whose provisional results were released in July 1998, indicates that the average population growth rate for the period 1981-98 was 2.6 percent per annum, a decline from previous intercensal rates and consistent with a decline in fertility in the 1990s.

All demographic analyses point to a decline in fertility in the 1990s. Over the past four decades there has been no other period when demographers could point with confidence to a decline of similar magnitude and duration (i.e. beyond year-to-year fluctuation). Demographic estimation in Pakistan is a treacherous business, however, because of the inaccurate reporting of ages and dates of events. This is a familiar problem for those who have followed demographic research on Pakistan: from the first demographic surveys carried out in the 1960s up to the present, systematic response errors have frustrated efforts to construct an accurate picture of levels and trends in fertility and its proximate determinants (Shah et al. 1986; Hashmi and Ahmed 1992). The more persuasive evidence that fertility decline is underway is provided by data on contraceptive practice. As indicated in Table 2, the fraction of currently married women reporting use of a method of contraception at the time of the survey remained below 10 percent through the 1980s. Surveys in the 1990s, in sharp contrast, reveal a marked increase in the contraceptive prevalence rate, from 12 percent in 1990-91 (PDHS) to 18 percent in 1994-95 (PCPS) to 24 percent in 1996-97 (PFFPS), a rise of roughly 2 percentage points per annum. This rise in the fraction of married women using con- 
Table 2 Trends in ever and current use of contraception among currently married women, by survey (percent)

\begin{tabular}{lcr}
\hline Survey & Ever use & Current use \\
\hline National Impact Survey (1968-69) & 12.1 & 5.5 \\
Pakistan Fertility Survey (1975) & 10.5 & 5.2 \\
Pakistan Contraceptive Prevalence Survey & & \\
$\quad(1984-85)$ & 11.8 & 9.1 \\
Pakistan Demographic and Health Survey & & \\
$\quad(1990-91)$ & 20.7 & 11.8 \\
$\begin{array}{l}\text { Pakistan Contraceptive Prevalence Survey } \\
\quad(1994-95)\end{array}$ & 28.0 & 17.8 \\
$\begin{array}{l}\text { Pakistan Fertility and Family Planning } \\
\quad \text { Survey (1996-97) }\end{array}$ & 36.4 & 23.9 \\
\hline
\end{tabular}

traception is the most compelling corroborating evidence that marital fertility is declining.

The method-specific trends in Table 3 reveal that increased use of modern methods, female sterilization and the IUD in particular, explains most of this overall trend (7.9 points out of the 12.1 percentage point increase from 1990-91 to 1996-97). This finding should not overshadow the substantial contribution of withdrawal, which alone accounts for almost one-third of the increase, more than any other single method. This is an unusual feature that distinguishes the early stages of Pakistan's marital fertility transition from other Asian transitions in the second half of the twentieth century (Population Council 1998a; Freedman 1995).

Urban-rural differentials in fertility provide further insight into the nature of the fertility transition. This differential widened in the 1980s (see Table 4), as marital fertility decline was initiated in the major cities, most notably Karachi (NIPS/IRD 1992). The differential has widened further in recent years, with the result that the urban-rural difference in the TFR exceeds 1.5 births as of the mid1990s. A corresponding urban-rural difference in contraceptive prevalence is also 
Table 3 Trends in current use of contraception by method among currently married women (percent)

\begin{tabular}{lccc}
\hline & \multicolumn{3}{c}{ Survey } \\
\cline { 2 - 4 } Method & $\begin{array}{c}\text { PDHS } \\
\mathbf{( 1 9 9 0 - 9 1 )}\end{array}$ & $\begin{array}{c}\text { PCPS } \\
\mathbf{( 1 9 9 4 - 9 5 )}\end{array}$ & $\begin{array}{c}\text { PFFPS } \\
\mathbf{( 1 9 9 6 - 9 7 )}\end{array}$ \\
\hline Any method & 11.8 & 17.8 & 23.9 \\
Any modern method & 9.0 & 12.6 & 16.9 \\
Condom & 2.7 & 3.7 & 4.2 \\
Pill & 0.7 & 0.7 & 1.6 \\
Injectable & 0.8 & 1.0 & 1.4 \\
IUD & 1.3 & 2.1 & 3.4 \\
Female sterilization & 3.5 & 5.0 & 6.0 \\
Other & 0.0 & 0.1 & 0.3 \\
Any traditional method & 2.8 & 5.2 & 7.0 \\
Rhythm & 1.3 & 1.0 & 1.9 \\
Withdrawal & 1.2 & 4.2 & 4.6 \\
Other & 0.3 & - & 0.5 \\
\hline
\end{tabular}

evident (36 percent and 18 percent in urban and rural areas respectively, according to the 1996-97 PFFPS). A closer examination of patterns over the past two decades reveals that a pronounced increase in fertility control began among the urban upper strata (as measured, for example, by female schooling) in the early 1980s and subsequently spread to other urban strata (Sathar and Mason 1993). All the available data indicate that contraceptive prevalence did not begin to increase in rural areas until the 1990s and therefore has not yet had a noticeable impact on fertility. The increase is found in each of the four provinces of Pakistan: as expected, Punjab has the highest prevalence levels, but the Northwest Frontier province experienced the most rapid rise in contraceptive use in the early 1990s. The upshot is a transition that in its early stages is following a conventional pattern in which reproductive intentions and behavior change first among 
Table 4 Trends in fertility by place of residence: Total fertility rates, by survey

\begin{tabular}{lccc} 
Survey & Period & Urban & Rural \\
\hline $\begin{array}{l}\text { Pakistan Fertility Survey (1975) } \\
\text { Pakistan Labour Force and Migration }\end{array}$ & $1970-74$ & 6.2 & 6.4 \\
$\quad$ Survey (1979) & $1975-79$ & 6.2 & 6.6 \\
$\begin{array}{l}\text { Pakistan Contraceptive Prevalence } \\
\quad \text { Survey (1984-85) }\end{array}$ & $1984-85$ & $5.5 / 6.1^{\mathrm{a}}$ & 6.2 \\
$\begin{array}{l}\text { Pakistan Demographic Survey (1992) } \\
\text { Pakistan Demographic and Health }\end{array}$ & 1992 & 6.2 & 7.3 \\
$\quad$ Survey (1990-91) & $1986-91$ & $4.7 / 5.2^{\mathrm{a}}$ & 5.6 \\
$\begin{array}{l}\text { Pakistan Contraceptive Prevalence } \\
\text { Survey (1994-95) }\end{array}$ & $1994-95$ & 4.5 & 6.3 \\
$\quad \begin{array}{l}\text { Pakistan Fertility and Family Planning } \\
\text { Survey (1996-97) }\end{array}$ & $1992-96$ & 4.2 & 5.7 \\
\hline
\end{tabular}

aThe PCPS and the PDHS divided urban areas into major urban areas and "other" urban areas; TFRs were higher in the latter category.

the upper social strata in the cities, with other urban residents and rural areas lagging behind, roughly six or seven years in this instance. To the extent it persists, the urban-rural differential has implications for national fertility trends because Pakistan has been rapidly urbanizing (as compared, for example, to other countries in South Asia). According to the 1998 Census, the urban population constitutes 33 percent of the total population (Population Census Organization 1998).

We place great weight on trends in contraceptive behavior because they represent deliberate efforts by couples to break from the reproductive regime that has characterized Pakistan in recent decades. A balanced assessment of this historic transformation must also consider the other major proximate determinants of fertility: nuptiality, postpartum practices, and induced abortion. Information on nuptiality is relatively abundant and shows a steady increase in the average age at first marriage of females throughout the five decades from Independence: singulate mean ages at first marriage calculated from census and survey data rise 
from 16.9 years in 1951 to 21.6 years in 1990-91 (PDHS) and 22.1 in 1996-97 (PFFPS) (NIPS/LSHTM 1998). The rise has been somewhat sharper in urban areas (Sathar 1997). Thus nuptiality change appears to have preceded the onset of marital fertility decline in Pakistan, as in other Asian countries in the twentieth century (Casterline 1994). The magnitude of the recent nuptiality change, however, is too slight to account for much of the estimated fertility decline in the 1990s.

Recent trends in postpartum behaviors are more difficult to discern because of gaps and incomparabilities in survey measurement over the past two decades. The available evidence suggests that the overall length of breastfeeding (unsupplemented and supplemented) has remained around 19 to 20 months from the 1970s to the present (WFS 1984; NIPS/IRD 1992) and therefore has not contributed to the recent fertility decline.

There are no reliable estimates of the incidence of induced abortion. ${ }^{5}$ But judging from qualitative investigations, induced abortion is a far more common method of birth control in Pakistan in the 1990s than had been previously assumed. Whether recourse to induced abortion has increased in the 1990s is even more difficult to ascertain, although this view is commonly volunteered by medical practitioners in Pakistan. Like withdrawal, induced abortion is a strategy for limiting fertility that falls outside the purview of the family planning program.

In summary, a review of the evidence on trends in the proximate determinants of fertility provides no basis for questioning either the validity of the estimated fertility decline in the 1990 s or the assertion that the decline is mainly due to increased practice of contraception within marriage.

\section{DETERMINANTS OF RECENT CHANGES IN FERTILITY}

We now turn to the question of which factors have led to this historic development. The context is laid out in Table 5, which presents trends in basic demographic, economic, and social indicators. If one accepts the classic hypothesis that fertility transition is a response to declines in mortality and improve- 
Table 5 Trends in demographic, economic, and social indicators

\begin{tabular}{lrrrc}
\hline & $\mathbf{1 9 6 0}$ & $\mathbf{1 9 7 0}$ & $\mathbf{1 9 8 0}$ & $\mathbf{1 9 9 0}$ \\
\hline Population size (millions) & 45.9 & 60.4 & 82.1 & 112 \\
Population growth (percent per year) & 2.7 & 2.8 & 2.9 & 3.0 \\
Population density per square km of & & & & \\
$\quad$ agricultural land & 200 & 248 & 324 & - \\
Life expectancy at birth (years) & 43 & 46 & 50 & 56 \\
Infant mortality rate (deaths/1000 & 162 & 143 & 126 & 103 \\
$\quad$ births) & 135 & 206 & 251 & 349 \\
GDP per capita (1987 US\$) & 22 & 25 & 28 & 32 \\
Percent urban & & & & \\
Percent literate & 15 & 21 & 24 & 35 \\
$\quad$ Total & - & 11 & - & 21 \\
$\quad$ Female & & & & \\
Primary school enrollment ratio & 30 & 40 & 39 & 44 \\
$\quad$ Total & 13 & 22 & 27 & 30 \\
$\quad$ Female & 6 & 17 & 67 & 87 \\
Radios per 1000 population & - & 2 & 10 & 17 \\
Televisions per 1000 population &
\end{tabular}

Sources: World Bank 1983, 1992; United Nations 1990, 1997.

ments in social and economic conditions, circumstances in Pakistan in the past four decades support conflicting expectations. By many criteria the country's fertility transition is several decades overdue: mortality fell steadily beginning in the 1950 s, resulting in very rapid population growth by the 1960s that continued through the 1980s. Urbanization, income, and literacy/schooling have increased steadily throughout these decades. Exposure to the mass media, as indicated by the prevalence of radios and televisions, increased dramatically beginning in the 1970s.

Offsetting these trends, however, were other conditions that acted against fertility reduction. The social environment has not been conducive to fertility change. By all measures, the status of Pakistani women is extremely low, even in 
comparison to other settings in South Asia (UN 1993). Pakistani women lack autonomy and have restricted mobility and minimal access to resources (Sathar et al. 1988; Sathar and Kazi 1997). Virtually all social indicators reveal vast gender inequities. Despite improvement, levels of literacy and school attainment remain extremely low among females (Table 5). The gender system gives disproportionate power to Pakistani men in decisionmaking about reproduction, and, as will be noted shortly, macroeconomic and related trends up to the 1990s did not provide men with a compelling reason to diverge from long-standing fertility practices. Further buttressing the existing reproductive regime has been the feudal structure of Pakistani society in which political and economic power has remained in the hands of a small number of families, especially in rural Sind and southern Punjab. These families have resolutely maintained pronatalist institutions and social values and have served as obstacles to the implementation of effective social-sector programs. The religious milieu, which has consistently maintained doubts about the moral acceptability of fertility control, constitutes an additional stumbling block. Nor did macroeconomic trends provide a rationale for fertility reduction prior to the 1990s. The economy performed strongly from the 1960s through the 1980s, with significant income growth resulting from impressive output in the agricultural sector and from substantial remittances from the Middle East, among other factors. GDP per capita grew at an average annual rate of 2.7 percent during the period 1970-85 (Hasan 1997). Income growth was inequitable and was not accompanied by investments in such social services as schooling, health, and housing (Hasan 1997).

In short, whatever the economic costs to Pakistani couples of large numbers of births, these costs seemed affordable in a period of income growth and, more to the point, were perceived as lower than the costs of challenging deeply held cultural precepts about reproduction and women's roles. This contrasts with the historical process in East Asia, where economic development of a different character fueled an upsurge in desires to restrict fertility (Greenhalgh 1988; Asian 
Development Bank 1997). Accompanying this set of cultural, social, and economic factors that propped up the existing fertility regime in Pakistan was weak and inconsistent political support for fertility reduction (Rosen and Conly 1996). The end result of all these forces was deep ambivalence at the household level about restricting fertility (Shah and Cleland 1993). A final factor, which perhaps should be viewed as an expression of the combined force of all the other factors, was the ineffectiveness of the family planning program, which left the vast majority of Pakistani couples without convenient access to adequate services (Rukanuddin and Hardee-Cleaveland 1992).

Each of these factors sustaining higher fertility has weakened in the 1990s. The macroeconomic data indicate that the steady economic growth of the 1970s and 1980s slowed considerably in the 1990s. Annual growth in GDP per capita declined to 1.2 percent in 1985-95 (Hasan 1997). The popular view is that the country is in the midst of a deep economic crisis-blamed on the structural adjustment and related conditionalities imposed by the IMF and the World Bankand many economists concur (Hussain et al. 1997; Khan and Aftab 1997). ${ }^{6}$ The economic crisis of the 1990s has compounded the stresses created by the longterm trend in rural areas toward land fragmentation and the more recent declines in returns to many agricultural crops (Choudhry 1997). Symptomatic of labor absorption problems in rural areas has been a growing stream of migrants from rural to urban areas in search of off-farm employment, and as a result the population is increasingly urbanized (see Table 5). The outcome of these macroeconomic forces has been an increase in unemployment, a decline in real wages, and consequent increases in poverty and income inequality (Hussain et al. 1997). In retrospect, the relatively healthy economy of the 1970s and 1980s fueled a resistance to social change that the economic crisis of the 1990s has undermined.

Accompanying the sense of economic stress, and in some respects accentuating it, have been changes in life styles and in parental aspirations for chil- 
dren. These changes have led to a pronounced increase in the relative cost of each child. The irony is that consumer aspirations have been rising at the same time as purchasing power has been shrinking in real terms. The greater concentration of the population in urban areas and the expanded exposure to the mass media (itself a result in part of urbanization) are the proximate causes of these changes. These trends are shown in Table 5 for the period 1960-90. The trends continue in the 1990s. For example, in the six-year period between the PDHS and the PFFPS the fraction of households with televisions increased from 27 to 38 percent (NIPS/ IRD 1992; NIPS/LSHTM 1998). This has occurred despite the travails of the economy and the decline in households' purchasing power, revealing the rapidly increasing attachment to modern consumer durables that itself must contribute to increases in the perceived costs of childbearing. A much more modern Pakistani life style is now transmitted through the media (particularly in advertising) to all corners of the country, including rural areas that were previously isolated. This in turn has had a direct bearing on how parents want to raise their children, with implications for standards of hygiene and health, tastes in clothing and consumer durables, and schooling aspirations. As Pakistanis themselves acknowledge in qualitative interviews (Population Council 1997d), all these changes make children more costly; this has driven down the demand for children and increased the perceived costs of unwanted births.

Changes in social structure, particularly in kinship relationships, are also underway. In Pakistan, as elsewhere in the northern half of the Indian sub-continent, the traditional kinship structure places comparatively little emphasis on the conjugal bond, which is viewed as a threat to highly valued consanguineous ties, intergenerational ties in particular (Vatuk 1987; Das Gupta 1996). This system also has the dual effect of restricting the decisionmaking power of spouses and, perhaps more importantly, marginalizing women (especially young married women). Although key elements of this system have been changing, these changes do 
not include expanded decisionmaking power for women. The evidence suggests that gender inequalities have been relatively constant in Pakistan, especially in rural areas. The vast majority of women continue to lack mobility and decisionmaking power within the household, and do not communicate effectively with their spouse (Sathar and Kazi 1997). We find no evidence that the overwhelming authority of men vis-a-vis their wives - regarding childbearing and other matters - has diminished as of the mid-1990s.

It is not an increase in the autonomy of women that has been decisive during the past decade but rather an increase in the autonomy of couples. Over the past three decades, kinship relations and household structures have evolved in a manner that has eroded the power of elders and other relatives, and as a result decisionmaking about family matters has become more nucleated. One indicator of this change is an increase in husband-wife discussion of fertility desires, reported by roughly one-third of respondents in the 1990-91 PDHS and by almost double that fraction in the 1994-95 PCPS (NIPS/IRD 1992; Population Council 1998b). A second indicator of this change is the increase in nuclear-family households. ${ }^{7}$ About one-half of the households in Pakistan are now nuclear (Population Council 1998b). When, as in Pakistan, a major cause of the growing predominance of nuclear households is rural-to-urban migration, in which couples with or without children move to towns and cities and set up separate households, it is much less likely that the new households are adjacent to households of extended kin. Reinforcing the effect of migration in freeing couples from the daily influence of extended kin is the fact that migration in Pakistan selects positively for literacy and schooling, among other reasons because of the job skills demanded by the nonagricultural labor markets in towns and cities (Kazi and Sathar 1996). ${ }^{8}$

Among the effects of the increasing independence of the conjugal unit has been greater consensus between spouses in their assessments of the costs and benefits of childbearing and related domestic issues. The economic and other 
costs of children are now perceived as more exclusively the responsibility of their parents, with the important consequence that Pakistani men have become much more cognizant of the costs of children. This development is reflected in recent survey and qualitative data that show both men and women acknowledging the advantages of restricting fertility, with women stressing health concerns and men the economic costs of bearing many children (Population Council 1997c). It is reflected, too, in the large contribution of male methods (withdrawal, condoms) to the recent increase in contraceptive prevalence (Table 3 ).

These broad economic and social changes in Pakistan are the fundamental causes of the observed changes in the 1990s in fertility and its proximate determinants - contraception in particular - that were summarized above. These fundamental causes have acted through a set of factors that are the more-direct causes of the observed changes. We now turn to these more-direct causes, classifying them into three categories:

- Changes in the demand for children.

- Changes in family planning services, e.g. their density and/or quality.

- Changes in other factors constraining contraceptive use, e.g. the social, psychic, and cultural "costs of contraception."

\section{DEMAND FOR CHILDREN}

The earliest demographic surveys in Pakistan in the 1960s did not reveal a demand for large families. The mean ideal family size reported in the 1968-69 National Impact Survey was 4.4 children and in the 1975 Pakistan Fertility Survey 4.1 children. As a result, the prevailing assumption for the past three decades has been that there is a substantial latent demand for fertility regulation in Pakistan (Sirageldin et al. 1976; Shah and Cleland 1993). As in an earlier paper (Sathar 1993), we take issue with this conventional interpretation. We feel that in the past latent demand for fertility regulation was in fact weaker than survey data have 
suggested, for four reasons: the limited autonomy of women, which for multiple and reinforcing reasons has worked against the adoption of fertility regulation practices (Sathar et al. 1988); the strong preference for male progeny; the relatively healthy state of the economy; and a political and cultural climate that looked unfavorably on the deliberate exercise of fertility control. During the 1990s, fertility demand has changed in two fundamental respects: the desired number of children has declined; and the attachment to fertility preferences has strengthened, i.e. preferences have "crystallized." We consider both developments.

One basic fertility demand parameter is ideal family size, i.e. responses to a question such as "If you could choose exactly the number of children to have in your whole life, how many would that be?" The available evidence suggests a sizable downward shift in ideal family size in the first half of the 1990s, from 4.1 in the 1990-91 PDHS to 3.6 in the 1994-95 PCPS. More valid measurement of fertility preferences is probably provided by responses to the question "Do you want another child?" The parity-specific percentages desiring no more children increase between 1990-91 and 1994-95 (see Table 6). The trend for the 20 years from the mid-1970s to the mid-1990s is curvilinear: a gradual decline in antinatalism from the 1975 PFS to the 1990-91 PDHS is followed by an increase in the first half of the 1990s.

Ideal family size and the figures in Table 6 relate to the number of children desired, but they say nothing about the strength of attachment to those desires. The strength of preferences can vary independently of the number of children desired, as a function for example of the perceived magnitude of the costs and benefits of an additional child (Bongaarts 1993). The strength of preferences is difficult to measure in demographic surveys. National surveys in Pakistan do not contain items that permit an assessment of trends in the strength of fertility preferences; hence we can only rely on what we have concluded from empirical data (quantitative and qualitative) collected in Pakistan over the past two decades. 
Table 6 Trends in fertility preferences by number of living children: Percentage of currently married women who want no more children, by survey

\begin{tabular}{lcccc}
\hline $\begin{array}{l}\text { Number of } \\
\text { living children }\end{array}$ & $\begin{array}{c}\text { PFS } \\
(\mathbf{1 9 7 5 )}\end{array}$ & $\begin{array}{c}\text { PCPS } \\
\mathbf{( 1 9 8 4 - 8 5 )}\end{array}$ & $\begin{array}{c}\text { PDHS } \\
(\mathbf{1 9 9 0 - 9 1 )}\end{array}$ & $\begin{array}{c}\text { PCPS } \\
(\mathbf{1 9 9 4 - 9 5 )})\end{array}$ \\
\hline 0 & 2 & 1 & 2 & 0 \\
1 & 7 & 4 & 4 & 12 \\
2 & 30 & 17 & 17 & 25 \\
3 & 48 & 36 & 36 & 51 \\
4 & 69 & 58 & 52 & 68 \\
5 & 78 & 75 & 63 & 78 \\
6 & 90 & 83 & 71 & 83 \\
$7+$ & 94 & 90 & 74 & 90 \\
Total & 49 & 43 & 40 & 52 \\
\hline
\end{tabular}

a Survey combines the responses "want no more" and "sterilized."

Sources: PFS (1975): Population Planning Council of Pakistan 1976: Table 3.1.1; PCPS (1984-85): Population Welfare Division, Government of Pakistan 1986: Table X.1; PDHS (1990-91): National Institute of Population Studies 1992: Table 8.1; PCPS (1994(95): Ministry of Population Welfare 1995: Figure 5.1.

These data suggest to us that the degree of conviction about stated preferences is much deeper in the 1990s than heretofore: there is a heightened consciousness of these preferences, the preferences are in sharper focus (i.e. more explicitly articulated), and the determination to realize them is stronger, in comparison to previous decades.

These changes in the demand for children are a response to the economic adversity and other social changes described above. Qualitative interviews conducted in the mid-1990s reveal the link between a growing sense of economic stress and an increased desire to restrict fertility (Population Council 1997c). In these unstructured interviews, Punjabi men and women were asked about the advantages and disadvantages of having many children and why they and/or their 
neighbors were motivated to practice family planning. Again and again, both men and women emphasized the costs of children and, especially, how it has become much harder to shoulder these costs in the difficult economic situation of the 1990s. ${ }^{9}$ While not clearly articulated by the respondents, one senses that the changes in life style aspirations and in childrearing aspirations that we noted above have also contributed to the conviction that the household is falling short economically. In inquiries carried out in earlier decades, the view that children have become unaffordable was not stated as often or as vociferously (NIPS n.d.). The diffusion of this conviction throughout the population appears to be a phenomenon of the 1990s.

Despite the growing sense that children are unaffordable, ideal family size remains in excess of three children. According to the parity-specific percentages of women wanting more births (Table 6), a small minority of women are content with two children or fewer: in the 1994-95 PCPS, only one-quarter of the women expressed a desire to stop at two surviving children, and 12 percent a desire to stop with one child. A far larger fraction of women must be prepared to limit their childbearing to two births or less if replacement-level fertility is to be achieved. Westoff and Bankole (1995) have demonstrated this through simulations in which various fractions of those women who express a desire to avoid pregnancy but are not using contraception are assumed to be using a method. Under two simulations using 1990-91 PDHS data, contraceptive prevalence would increase from 12 percent to 27 percent and 38 percent. These would result in declines in the TFR from 5.4 births per woman (the PDHS direct estimate) to 4.4 and 3.6, respectively, a range that roughly brackets the most recent estimates of the average ideal number of children. These would be substantial declines in relation to present fertility levels but would leave fertility far above replacement nevertheless.

Son preference partially accounts for the persistence of the desire for a moderate number of births. Many women with three or more surviving children 
want to have more children in the hope of having a son (Mahmood 1996). Analyses of survey data collected in the 1990s consistently show that son preference affects both fertility preferences and contraceptive use. In particular, even among those women indicating a desire to postpone the next pregnancy or to avoid having another pregnancy altogether, the likelihood of using contraception increases with the number of surviving sons (Population Council 1997a; Sathar and Kazi 1997). Two sons remain the basic minimum in the minds of most couples, and there is no evidence that this view is waning significantly even in urban areas. This powerful and highly conscious son preference is to be expected given the many social and economic structures that devalue females and the reliance in a patrilineal system on sons for support in old age (Sathar and Kazi 1997). Other forces are responsible for a continuing preference for three or more children. Despite substantial declines in the past four decades, infant and child mortality levels remain relatively high (Table 5), and insecurity about child loss continues to be an oft-cited reason in unstructured interviews for having a larger than ideal family size (Population Council 1997c). Furthermore, a larger family size increases the likelihood that one or more children might enjoy success in employment or marriage, thereby improving the standing of the family. Particularly in the large agricultural sector, children's labor continues to be valued. Most Pakistani households view children as the most stable form of social and economic security (Sathar and Kazi 1997).

\section{Family Planning Services}

A second class of explanations for the onset of fertility decline in Pakistan emphasizes improvements in family planning services, both in their density and their quality. From its inception through the 1980s, the national family planning program fell short on both counts (Robinson et al. 1981; Rukanuddin and HardeeCleaveland 1992). There are solid grounds for believing that the provision of 
family planning services has improved in the 1990s, extending a trend that began in the 1980s, judging by Ross et al.'s family planning program effort scores (Ross et al. 1992). Several new schemes that were launched in the Eighth Five-Year Plan (1993-98) have begun to take root (Rosen and Conly 1996). Two innovations are noteworthy. The social marketing of contraceptives, begun in 1986, has gained momentum in the 1990s. Despite some setbacks, social marketing has probably improved accessibility in urban areas (Davies and Agha 1997; Agha and Davies 1998). The Village-Based Family Planning Workers program, launched on a pilot basis in 1992, now provides family planning services and advice in about 8000 villages (Population Council 1997b).

Other initiatives may have contributed to the improvement of the family planning service environment in the 1990s. The Prime Minister's primary health care program was launched in 1994, with another cadre of community-based female workers posted in both urban slums and rural areas. Thirty thousand such workers are believed to have been deployed with the responsibility to provide primary health care, including family planning, to the communities from which they were recruited (Ministry of Health 1996). Furthermore, Ministry of Health outlets, including rural health centers and basic health units, now have a stronger mandate to provide family planning.

Finally and perhaps most significantly, radio and television campaigns promoting family planning have picked up momentum, in terms of both their frequency and the explicitness of the messages. The percentage of women who reported that they had heard or seen a family planning message more than doubled between the 1990-91 PDHS and the 1994-95 PCPS, exceeding 60 percent in the latter survey (NIPS/IRD 1992; Ministry of Population Welfare and Population Council 1995). The radio and television messages both legitimize family planning practice and offer concrete information about how contraceptives might be obtained. A recent analysis comparing IEC impact in Bangladesh, India, and Pakistan shows vast im- 
provements in the reach of family planning messages in the Pakistani media and in their association with contraceptive adoption (Westoff and Bankole 1998).

Undoubtedly, then, family planning program activities have improved in the 1990s and probably deserve some credit for the recent increase in contraceptive prevalence and the resulting decline in fertility. But the important enhancements in services were implemented only in the mid-1990s and hence cannot be given credit for the sharp increase in contraceptive prevalence in the first half of the decade. In our judgment, the contribution of improvement in family planning services has been minor as compared to the contribution of the other major factors (changes in the demand for children, reduction in other costs of contraception). An indication that this is so is the fact that a substantial fraction of the increase in contraceptive prevalence in the 1990s has been due to use of withdrawal: 3.4 points out of the 12.1 percentage point increase between 1990-91 and 1996-97 (see Table 3). Withdrawal is a means of avoiding pregnancy that is free of any dependence on contraceptive supplies or services and, indeed, is often regarded as a sign that fertility decline is more the result of increasing motivation to avoid pregnancy than of improvements in the means to do so (Santow 1995).

Family planning services remain deficient in many respects. For example, basic coverage of the population is deficient in both urban and rural areas, especially the latter. Various criteria classify far less than half of the population as having convenient access to any type of services. One study concludes that family planning clinics (the Family Welfare Centres) are accessible to only 10 percent of the population, with only 5 percent living within easy walking distance (Rosen and Conly 1996). Data from the 1994-95 PCPS show an average traveling time to a family planning service delivery point of 60 minutes in rural areas (as compared to 15 minutes in urban areas). The nearest facility is three or more miles away for 61 percent of never users in rural areas and for 13 percent of never users in urban areas. Clearly clinics are far closer on average for women in urban areas, but access is a serious obstacle nevertheless because of the many restric- 
tions on women moving about outside their dwellings. The upshot is that a small minority of women report having had contact with a family planning worker (Ministry of Population Welfare and Population Council 1995), and this is essentially unchanged since the late 1970s (Syed 1979). The social marketing and the Village-Based Family Planning Workers schemes hold much promise of significantly improving access to supplies and services, although rural areas remain largely untouched by social marketing (Davies and Agha 1997).

Beyond access, serious problems affect the quality of family planning services. The situation analyses that have been carried out are unambiguous on this point (e.g. Cernada et al. 1993). Outlets rarely offer a choice of methods and informed advice about alternative methods, often do not have sufficient supplies on hand, and typically lack an adequate number of trained staff. Pakistani couples concur with this evaluation: in unstructured interviews, men and women (especially rural residents) repeatedly describe providers as poorly trained and unmotivated and the contraceptive supplies as defective and unreliable (Population Council 1997c). The majority of women, especially in rural areas, seek family planning services in large hospitals; other types of outlets, even where available, are rarely visited (Population Council 1998b).

This harsh evaluation of the family planning program is based on evidence from careful local studies. Like Freedman (1995), we feel that Ross et al.'s (1992) rating of the program effort in Pakistan as "moderate" is too favorable, probably reflecting undue weight given to policy rhetoric and formal bureaucratic structure and too little weight given to the extent and quality of the services actually provided to Pakistani couples.

\section{OTHER COSTS OF CONTRACEPTiON}

Our third explanation for recent changes is that other forces that hinder contraceptive use have weakened. Many types of evidence suggest that the costs of using contraception in Pakistan go well beyond the financial and time costs of 
obtaining family planning supplies and services of acceptable quality. We refer to social, psychic, health, and cultural factors that, together with financial and time costs, constitute what Easterlin (1975) terms the "costs of contraception." These factors are not easily measured, hence their contribution is difficult to assess empirically. A reading of the literature on fertility in Pakistan since the 1960s and evidence obtained through in-depth qualitative and quantitative research conducted in Punjab province in 1996 suggest that three obstacles to fertility control behavior weakened significantly in the 1990s: the view that family planning is proscribed by moral and religious codes (Shah and Shah 1984); the view that extendedfamily members, and parents in particular, have a rightful voice in the fertility decisions of a husband and wife; and the view that contraceptive practice threatens men's authority over women. For contraceptive practice to become widespread, these views must be undermined through a process that legitimizes couples' capacity to take deliberate actions to avoid pregnancy (Shah and Cleland 1993).

Such a process has been evident in Pakistan in the 1990s, driven by related social and economic changes. Among the most important of these have been the changes in family structure described above, which have eroded the power of elders and other extended kin, especially among migrants to urban areas (Kazi and Sathar 1996). This erosion of power undermines the second of the obstacles just identified. We have argued that one consequence of this change in family structure is greater concurrence, and most likely better communication, between spouses about the costs of children and a heightened sense that these costs are shared. For example, in data collected in 1996 Punjabi women report little hesitance in approaching their husbands about using contraception (Population Council 1997a). This has meant, in turn, that family planning practice does not threaten gender relations to the extent it did in the past; in the 1990s, to use contraception is not to act against the interests of the husband. Moreover, couples often opt for those contraceptive methods - withdrawal, condoms - that are male-controlled (see Table 3), further reducing the threat contraception might pose to patriarchal 
interests. Finally, the realization that raising children is costly, and that these costs are increasing, counters the conviction that use of contraception is immoral. In unstructured interviews, male respondents in particular cite the moral duty to provide for children's needs, a duty that is difficult to fulfill with a large family (Population Council 1997c). These factors have led to greater legitimization of contraception, reinforced by the convincing antinatalist pronouncements of government officials since Prime Minister Nawaz Sharif's public endorsement of family planning in 1991 (repeated in 1997 and 1998), by the intensification of media campaigns espousing family planning, and by the greater visibility of family planning program activities at local levels, particularly in rural areas.

What has been underway in Pakistan - first in urban areas, more slowly in rural areas (probably beginning in the Punjab) — is a social dynamic in which family planning has acquired the acceptability that it lacked in the past. There is a shift of values away from traditional to modern, and a shift in the locus of decisionmaking from extended kin to the conjugal couple. The dynamic has its own momentum: as some Pakistani couples begin to practice contraception and this becomes known, the same choices become more acceptable to other couples. Couples may also acquire useful information from each other, about where to obtain services and how to cope with health side effects of contraception, for example. In this fashion the social, psychic, and cultural barriers to contraception begin to collapse, very much resembling a "contagion" process. This dynamic may well characterize most fertility transitions at some stage (Montgomery and Casterline 1996). It provides one of the more plausible and parsimonious explanations for the sudden increase in contraceptive prevalence in Pakistan in the 1990s after several decades during which surveys repeatedly suggested that latent demand for fertility control far exceeded contraceptive practice.

While certain costs of contraception may be on the wane, others remain as serious obstacles to adopting and continuing use of contraception. As a result, despite the recent sharp increase in contraceptive prevalence, "unmet need for 
contraception" (i.e. non-use of contraception by women at risk of pregnancy who desire to avoid becoming pregnant) remains high—on the order of one-third of currently married women (Westoff and Bankole 1995; Population Council 1998b; NIPS/LSHTM 1998). Indeed, comparison of estimates from the three national surveys conducted in the 1990s suggests that unmet need may even be on the increase, a common pattern in the early stages of fertility transition as declines in demand for children outpace increases in contraceptive use (Bongaarts 1997). In a recent in-depth study conducted in the Punjab on factors underlying unmet need, three factors emerge as the most decisive obstacles to family planning: women's perceptions that their husbands disapprove; fear of detrimental health side effects of contraception; and concerns about the social, cultural, and religious acceptability of birth planning (Population Council 1997a). ${ }^{10}$ These and other considerations conspire to make many women feel that the decision to use contraception is both unacceptable on social and cultural grounds and against their best interests, even if they wish to avoid pregnancy. In transcripts from unstructured interviews, the anxiety that women feel about the decision whether or not to use contraception is almost palpable. Conflicting forces encourage and discourage family planning practice. The resulting ambivalence makes it difficult for many women to use contraception, especially given the effort required to obtain a method in the many communities where family planning services are distant and/or of poor quality.

These considerations are compounded by the limited autonomy of women in this and other spheres of life, which as noted above does not appear to be changing to any meaningful extent. The experience of East Asia in the period 1950-80 demonstrated that fertility can decline to relatively low levels despite the low status of women; there are no grounds for asserting that increased autonomy is a precondition for fertility transition. Nevertheless, the lack of female autonomy almost certainly hinders the transition from a high to low fertility re- 
gime: the expression of women's desire for fewer children is muted, and the range of contraceptive choices is restricted (Jejeebhoy 1995). In addition, many women who wish to postpone or terminate childbearing perceive that their husbands desire more children and oppose contraceptive practice. In fact, empirical data collected in the mid-1990s indicate that men have more positive views about contraception (and particular contraceptive methods) and are less pronatalist than their wives assume (Population Council 1997a). However, given the limited communication between spouses and the unequal balance of power in gender relations, these misperceptions by wives are not readily corrected and are a stronger deterrent than would be the case in many other settings. The result is that Pakistani women often take the safe route of not implementing their fertility preferences, in deference to the presumed pronatalism of their husbands. It is hardly surprising that men have played a decisive role in the developments of the 1990s, as reflected, for example, in the relatively large contributions of increased use of withdrawal and condoms.

\section{CONCLUSIONS}

Evidence is accumulating that a transition in marital fertility behavior has begun in Pakistan in the 1990s. The evidence is of several types and comes from multiple and independent sources. In searching for the forces underlying this development, we have emphasized changes in the demand for children - a crystallization of existing desires for smaller families, combined with a decline in family size desires (itself reflecting broader macroeconomic and social changes) - as well as changes in the social, psychic, and cultural costs of contraception. We give less credit to improvements in family planning services, although they have made a contribution. In examining the obstacles to further changes in fertility, in contrast, we have stressed the immediate need for improvements in family planning services and for further reductions in other costs of contraception. Tak- 
ing this assessment of the constraints on further change as a starting point, we can sketch likely scenarios for the next decade or so, and we can identify the types of policies that might render certain scenarios more or less likely.

Because a large fraction of currently married women have unmet need for contraception, in theory a substantial increase in contraceptive use and a corresponding decline in fertility could occur without any change in fertility preferences (Shah and Cleland 1993). ${ }^{11}$ This is an important conclusion from the standpoint of near-term policy formulation and program development. But from the standpoint of the longer-term goal of achieving replacement-level fertility in $\mathrm{Pa}$ kistan, the demand for children must be regarded as the most serious constraint. As noted above, Westoff and Bankole (1995) estimate that, were existing unmet need to be satisfied, the TFR would remain in the range $3.6-4.4$ births per woman, a level that implies continued rapid population growth.

A first point is that the downward trend in the demand for children apparent in the early 1990s is likely to continue to exert downward pressure on fertility. As a natural outcome of a growing awareness that marital fertility can be deliberately regulated, the strength of attachment to desires for moderate or small numbers of children (i.e. less than five) will grow, while simultaneously the fraction of couples desiring large numbers of children will decline, in response to the trends in economic aspirations and perceived costs of children described above. Pakistan is increasingly urbanized, and childrearing and consumer aspirations that have antinatalist implications are spreading to lower socioeconomic strata and rural areas. Most importantly, the economic situation continues to deteriorate, accompanied by the widespread sense of economic distress. Hence we expect that a growing fraction of Pakistani couples will wish to limit their number of children to less than four. Eventually this will undermine the marked differentials in reproductive behavior according to place of residence (urban or rural) and level of schooling that have typified the past two decades. 
Are these changes in demand likely to be matched by rises in contraceptive prevalence and declines in fertility? In the long run the answer must be yes. In the short run, however, the answer is dependent on the extent of changes in family planning service delivery. A particular need is greater coverage in rural areas, where the limited mobility of women makes even modest travel distances to family planning services and supplies an imposing barrier to the adoption and continued use of contraception. One strategy would be to depend mainly on an extensive network of private services in urban areas (here we second Rukanuddin and Hardee-Cleaveland 1992 and Rosen and Conly 1996 in calling for greater reliance on the private sector, both NGOs and medical practitioners), with public resources then freed up for more extensive deployment in rural areas. Efforts must also be made to upgrade the quality of services. Interviews in the 1996 study in Punjab reveal the dim view of public-sector services held by many women and men. In short, given the heightened motivation to restrict fertility, the key in the short run to maintaining and perhaps even accelerating the fertility transition in Pakistan will be improvements in family planning services.

The onset of the transition has been triggered by changes in fertility demand and by reductions in the social, psychic, and cultural costs of contraception. None of these costs has been entirely eliminated. If family planning services remain inadequate, then we expect that unmet need for family planning will remain at its current high level or even increase. Under the most desirable scenario the ongoing declines in demand for children would be accompanied by radical improvements in the supply and quality of family planning services. This scenario offers the conditions for a very rapid fertility decline in Pakistan over the next decade or so. 


\section{Notes}

1 On the basis of a detailed analysis of the birth histories collected in the 1975 Pakistan Fertility Survey, Alam (1984) concluded that fertility decline had begun in the early 1970s. This conclusion was later refuted by Retherford et al. (1987), who demonstrated that the impression of decline could almost certainly be attributed to reporting errors. Similarly, a decline in marital fertility in the late 1980s evident in direct estimates from the Pakistan Demographic and Health Survey of 1990-91 (NIPS/IRD 1992) disappears when the data are subjected to more rigorous analyses that adjust for problems of data quality (Curtis and Arnold 1994; Juarez and Sathar forthcoming).

2 A far lower TFR for Nepal is proposed by Dangol et al. (1997). On the basis of analysis of survey data from the 1970s to the early 1990s, they conclude that the TFR as of 1991 was 4.78. According to their analysis, the marital fertility transition in Nepal was progressing relatively rapidly as of the late 1980 s.

3 This is consistent with the United Nations (1996) estimate for the TFR in 1995 of 5.5 births per woman.

4 The PFFPS estimates will need to be scrutinized. In Pakistan, fertility estimates derived from birth histories typically are downwardly biased for the period immediately preceding the survey. Even so, it seems likely that as of 1998 the TFR falls in the range of 5.0 - 5.5 - rather high by international and regional standards but one birth less than the level that characterized the previous 30 years.

5 In the 1994-95 PCPS, 5.9 percent of women aged 35 and older reported that their most recent pregnancy ended in an abortion, spontaneous or in- 
duced. Less than 1 percent of the women reported an induced abortion. Recognizable spontaneous abortions should be on the order of 15 to 20 percent among women in this age group.

6 The rupee has weakened substantially since the early 1980s, driving up the local price of essential items that are import-dependent such as cooking oil, kerosene, and fertilizer. The consumer price index trebled between 1982 and 1995 (Hasan 1997), and according to authoritative (but unofficial) estimates the rate of inflation in the costs of basic goods in the 1990s has exceeded 20 percent per annum.

7 A number of independent sources confirm this assertion. We have compared the distribution of households by type in the 1975 PFS and the 199091 PDHS. The comparison is not exact, because of definitional differences in the household structure variables in the two data sets. Our comparison probably understates the amount of change. We find that the percentage of households that are nuclear has been relatively stable in rural areas but has increased by ten percentage points in urban areas. This is consistent with our argument below that urban Pakistani couples in particular are experiencing new-found independence in reproductive decisionmaking, as reflected in the much greater recent change in fertility in urban areas.

8 There is good evidence that household structure is associated with women's autonomy. Data collected in the Punjab in 1993 show that women living in nuclear households have greater autonomy: 62 percent and 22 percent of women living in nuclear households make decisions regarding schooling of children and major household purchases, respectively, compared to 46 percent and 12 percent of women living in extended households (Sathar and Kazi 1997). The same study finds that women living in nuclear households have greater mobility; for example, 40 percent of these women are 
able to go to a health center alone, compared to 19 percent of those living in extended households.

9 Ironically, the economic adversity created by the combination of stagnant wages and rising costs of basic goods has made contraceptives less affordable for most households. This circumstance is especially relevant for methods such as injectables, oral contraceptives, and condoms that are supplied primarily by the private sector. Agha (1998) shows strong crosssectional associations between the use of some of these methods and household income.

10 A similar set of factors is identified in Hashmi et al.'s (1993) research in the early 1990s on reasons for non-use.

11 Our 1996 research in Punjab province (Population Council 1997a) revealed that weak attachment to stated fertility preferences is among the reasons for unmet need for contraception. It follows that increased contraceptive practice could also result from further crystallization of preferences and stronger convictions about those preferences.

\section{References}

Agha, Sohail. 1998. "Is low income a constraint to contraceptive use among the Pakistani poor?” PSI Research Division Working Paper No. 15, Washington, D.C.: Population Services International.

Agha, Sohail and John Davies. 1998. "Contraceptive social marketing in Pakistan: Assessing the impact of the 1991 condom price increases on sales and consumption," PSI Research Division Working Paper No. 14, Washington, D.C.: Population Services International.

Alam, Iqbal. 1984. "Fertility levels and trends," in Iqbal Alam and Betzy Dinesen (eds.), Fertility in Pakistan: A Review of Findings from the Pakistan Fer- 
tility Survey, pp. 65-80. Voorburg, Netherlands: International Statistical Institute.

Asian Development Bank. 1997. Emerging Asia: Changes and Challenges. Manila: Asian Development Bank.

Bongaarts, John. 1993. "The supply-demand framework for the determinants of fertility: An alternative implementation," Population Studies 47(3): 437456.

Bongaarts, John. 1997. "Trends in unwanted childbearing in the developing world," Studies in Family Planning 28(4): 267-277.

Casterline, John B. 1994. "Fertility transition in Asia," in Therese Locoh and Veronique Hertrich (eds.), The Onset of Fertility Transition in Sub-Saharan Africa, pp. 69-86. Liege: Derouaux Ordina.

Cernada, George P., A.K. Ubaidur Rob, Safia I. Ameen, and Muhammed Shafiq Ahmad. 1993. "A situation analysis of family welfare centres in Pakistan," Working Paper No. 4, Population Council/Islamabad. Islamabad: Population Council.

Choudhry, Ghaffar. 1997. "Pakistan's agricultural development since independence: Intertemporal trends and explanations." Paper presented at the 13th Annual General Meeting of the Pakistan Society for Development Economists, Islamabad.

Cleland, John, James F. Phillips, Sajeda Amin, and G.M. Kamal. 1994. The Determinants of Reproductive Change in Bangladesh: Success in a Challenging Environment. Washington, D.C.: World Bank.

Curtis, Sian L. and Fred Arnold. 1994. "An evaluation of the Pakistan DHS Survey based on the reinterview survey," Demographic and Health Surveys Occasional Papers, No. 1, Calverton, Maryland: Macro International.

Dangol, Bishnu Das, Robert D. Retherford, and Shyam Thapa. 1997. "Declining fertility in Nepal," Asia-Pacific Population Journal 12(1): 33-54. 
Das Gupta, Monica. 1996. "Life course perspectives on women's autonomy and health outcomes," Health Transition Review, Supplement to Volume 6: 213232.

Davies, John and Sohail Agha. 1997. "Ten years of contraceptive social marketing in Pakistan: An assessment of management, outputs, effects, costs and cost-efficiency, 1987-1996," PSI Research Division Working Paper No. 7, Washington, D.C.: Population Services International.

Easterlin, Richard. 1975. "An economic framework for fertility analysis," Studies in Family Planning 6(3): 54-63.

Federal Bureau of Statistics. 1997. Pakistan Demographic Survey 1992. Karachi: Statistics Division.

Freedman, Ronald. 1995. "Asia's recent fertility decline and prospects for future demographic change," Asia-Pacific Population Research Reports No. 1, Honolulu: East-West Center, Program on Population.

Government of Pakistan. 1965. Third Five Year Plan. Karachi: Planning Commission.

Greenhalgh, Susan. 1988. "Fertility as mobility: Sinic transitions," Population and Development Review 14(4): 629-674.

Hasan, P. 1997. 'Learning from the past: A fifty year perspective of Pakistan's development." Paper presented at the 13th Annual General Meeting of the Pakistan Society for Development Economists, Islamabad.

Hashmi, Sultan S. and Tauseef Ahmed. 1992. "Shy/silent users of contraception: Further evidence," Pakistan Population Review 3(1): 19-40.

Hashmi, Sultan S., Khushnood Alam, and Aysha Sheraz. 1993. Non-Users and Unmet Need for Contraception. Islamabad: National Institute of Population Studies.

Hussain, Akmal, et al. 1997. Overcoming Poverty. The Report of the Task Force on Poverty Eradication, May 1997, Islamabad. 
Jejeebhoy, Shireen J. 1995. Women's Education, Autonomy, and Reproductive Behaviour: Experience from Developing Countries. Oxford: Clarendon Press.

Juarez, Fatima and Zeba Sathar. Forthcoming. "Emerging evidence of fertility change in Pakistan," in Basia Zaba and Alaka Basu (eds.), Brass Tacks. Oxford: Oxford University Press.

Kazi, Shahnaz and Zeba Sathar. 1996. "Gender and development: Searching for explanations for fertility change in rural Pakistan." Paper presented at the IUSSP Seminar on Comparative Perspectives on Fertility Transition in South Asia, Rawalpindi, December.

Khan, Shahrukh Rafi and Safiya Aftab. 1997. "Structural adjustment, labour, land, and the poor in Pakistan," The Lahore Journal of Economics 2(1).

Mahmood, Naushin. 1996. "Gender differences in fertility desires and son preference in Pakistan: Implications for reproductive behaviour.” Paper presented IUSSP Seminar on Comparative Perspectives on Fertility Transition in South Asia, Rawalpindi, December.

Ministry of Health. 1996. The Prime Minister's Programme for Family Planning and Primary Health Care, Second Evaluation. Islamabad: Ministry of Health.

Ministry of Population Welfare and the Population Council. 1995. Pakistan Contraceptive Prevalence Survey 1994-95. Islamabad: Population Council.

Montgomery, Mark R. and John B. Casterline. 1996. "Social learning, social influence, and new models of fertility," in John B. Casterline, Ronald D. Lee, and Karen A. Foote (eds.), Fertility in the United States: New Patterns, New Theories, pp. 151-175. Population and Development Review, Supplement to Volume 22.

National Institute of Population Studies (NIPS) and IRD/Macro International Inc. 1992. Pakistan Demographic and Health Survey 1990/1991. Columbia, Maryland: IRD/Macro International. 
National Institute of Population Studies (NIPS) / London School of Hygiene and Tropical Medicine (LSHTM). 1998. Pakistan Fertility and Family Planning Survey 1996-1997. Islamabad: National Institute of Population Studies.

National Institute of Population Studies (NIPS). n.d. The Economic Value of Children. Islamabad.

Population Census Organization. 1998. Provisional Results of Fifth Population and Housing Census, Islamabad.

Population Council. 1997a. The Gap Between Reproductive Intentions and Behaviour: A Study of Punjabi Men and Women. Islamabad: Population Council.

Population Council. 1997b. "Initial performance and impact of VBFPWs in four districts in Punjab," Research Report No. 5. Islamabad: Population Council.

Population Council. 1997c. "Exploring barriers to contraception in Pakistan: Findings from qualitative research." Islamabad: Population Council.

Population Council. 1997d. The Village Relations Study. Population Council Briefing Paper. Islamabad: Population Council.

Population Council. 1998a. "A Qualitative Investigation into the Use of Withdrawal” Research Report No. 6. Islamabad: Population Council.

Population Council. 1998b. Pakistan Contraceptive Prevalence Survey 199495: Final Report. Islamabad: Population Council.

Population Planning Council of Pakistan. 1976. Pakistan Fertility Survey: First Report. Islamabad: PPCP.

Population Welfare Division, Government of Pakistan. 1986. Pakistan Contraceptive Prevalence Survey 1984-85. Islamabad: Government of Pakistan.

Retherford, Robert, G.M. Mirza, M. Irfan, and Iqbal Alam. 1987. "Fertility trends in Pakistan: The decline that wasn't," Asia and Pacific Forum 1(1): 3-10. 
Robinson, Warren C., Makhdoom A. Shah, and Nasra M. Shah. 1981. "The family planning program in Pakistan: What went wrong?” International Family Planning Perspectives 7(3): 85-92.

Rosen, James E. and Shanti R. Conly. 1996. Pakistan's Population Program: The Challenge Ahead. Washington, D.C.: Population Action International (Country Study Series No. 3).

Ross, John A., W. Parker Mauldin, Steven R. Green, and E. Romana Cooke. 1992. Family Planning and Child Survival Programs as Assessed in 1991. New York: Population Council.

Rukanuddin, Abdul Razzaque and Karen Hardee-Cleaveland. 1992. "Can family planning succeed in Pakistan?" International Family Planning Perspectives 18(3): 109-115.

Santow, Gigi. 1995. "Coitus interruptus and the control of natural fertility," Рориlation Studies 49(1): 19-44.

Sathar, Zeba A. 1993. "The much awaited fertility decline in Pakistan: Wishful thinking or reality?" International Family Planning Perspectives 19(4): 142-146.

Sathar, Zeba A. 1997. "La croissance demographique an Pakistan: Une maitrise delicate," in J.-C. Chasteland and J.-C. Chesnais (eds.), La Population du monde: enjeux et problemes. Paris: Presses universitaires de France.

Sathar, Zeba, Nigel Crook, Christine Callum, and Shahnaz Kazi. 1988. "Women's status and fertility change in Pakistan," Population and Development Review 14(3): 415-432.

Sathar, Zeba A. and Shahnaz Kazi. 1997. Women's Autonomy, Livelihood, and Fertility: A Study of Rural Punjab. Islamabad: Pakistan Institute of Development Economics.

Sathar, Zeba A. and Karen Mason. 1993. "How female education affects reproductive behavior in urban Pakistan," Asian and Pacific Population Forum 6(4). 
Shah, Iqbal H., Thomas Pullum, and M. Irfan. 1986. "Fertility in Pakistan during the 1970's," Journal of Biosocial Science 18(2): 215-229.

Shah, Iqbal H. and John G. Cleland. 1993. "High fertility in Bangladesh, Nepal, and Pakistan: Motives versus means," in Richard Leete and Iqbal Alam (eds.), The Revolution in Asian Fertility: Dimensions, Causes, and Implications, pp. 175-207. Oxford: Clarendon Press.

Shah, Nasra M. and Makhdoom A. Shah. 1984. "From non-use to use: Prospects of contraceptive adoption," in Iqbal Alam and Betzy Dinesen (eds.), Fertility in Pakistan: A Review of Findings from the Pakistan Fertility Survey, pp. 149-162. Voorburg, Netherlands: International Statistical Institute.

Sirageldin, Ismail, Douglas Norris, and J. Gilbert Hardee. 1976. "Family planning in Pakistan: An analysis of some factors constraining use," Studies in Family Planning 7(5): 144-154.

Syed, Sabiha H. 1979. "Communications channels and family planning in Pakistan," Studies in Family Planning 10(2): 53-60.

United Nations. 1990. Human Development Report 1990. New York: Oxford University Press.

United Nations. 1993. Women's Status and Fertility in Pakistan: Recent Evidence. New York: United Nations, Department for Economic and Social Information and Policy Analysis.

United Nations. 1996. World Population Prospects: The 1996 Revision. New York: United Nations, Department for Economic and Social Information and Policy Analysis.

United Nations. 1997. Human Development Report 1997. New York: Oxford University Press.

Vatuk, Sylvia. 1987. "Authority, power, and autonomy in the life cycle of the North Indian woman," in P. Hockings (ed.), Dimensions of Social Life. New York: de Gruyter Press. 
Westoff, Charles F. and Akinrinola Bankole. 1995. "Unmet need: 1990-1994." Demographic and Health Surveys Comparative Studies. No. 16. Calverton, Maryland: Macro International.

Westoff, Charles F. and Akinrinola Bankole. 1998. "Mass media and reproductive behavior in Pakistan, India, and Bangladesh." Manuscript: Office of Population Research, Princeton University.

World Bank. 1983. World Tables: Third Edition: Baltimore: Johns Hopkins University Press.

World Bank. 1992. World Development Report 1992. New York: Oxford University Press.

World Fertility Survey (WFS). 1984. World Fertility Survey: Major Findings and Implications. Voorburg, Netherlands: International Statistical Institute. 


\title{
POLICY RESEARCH DIVISION WORKING PAPERS
}

\author{
Recent Back Issues
}

1996

*83 Sajeda Amin, Ian Diamond, and Fiona Steele, "Contraception and religious practice in Bangladesh."

84 John B. Casterline, Aurora E. Perez, and Ann E. Biddlecom, "Factors underlying unmet need for family planning in the Philippines."

85 Geoffrey McNicoll, "Governance of fertility transition: Regularity and duress."

*86 John Bongaarts, "Population pressure and the food supply system in the developing world."

87 Sajeda Amin, "Family structure and change in rural Bangladesh."

*88 John Bongaarts and Susan Cotts Watkins, "Social interactions and contemporary fertility transitions."
*89 Cynthia B. Lloyd and Mark R. Montgomery, "The consequences of unintended fertility for investments in children: Conceptual and methodological issues."

* 90 Zeba Sathar and Sonalde Desai, "Work patterns in rural Pakistan: Intersections between gender, family, and class."

*91 Mark R. Montgomery, "Learning and lags in mortality perceptions."

92 Ann E. Biddlecom, John B. Casterline, and Aurora E. Perez, "Men's and women's views of contraception."
93 James F. Phillips, Fred N. Binka, Martin Adjuik, Alex Nazzar, and Kubaze Frank Adazu, "The determinants of contraceptive innovation: A case-control study of family planning acceptance in a traditional African society."
94 John Bongaarts and Sajeda Amin, "Prospects for fertility decline and implications for population growth in South Asia."

95 Barbara S. Mensch and Cynthia B. Lloyd, "Gender differences in the

* No longer available 
schooling experiences of adolescents in low-income countries: The case of Kenya."

96 Martin Brockerhoff and Ellen Brennan, "The poverty of cities in the developing world."

97 Carol E. Kaufman, "Reproductive control in South Africa."

98 John Bongaarts, "Trends in unwanted childbearing in the developing world."

99 Mary Arends-Kuenning, "How do family planning workers' visits affect women's contraceptive behavior in Bangladesh?"

100 Mark R. Montgomery and Cynthia B. Lloyd, "Excess fertility, unintended births, and children's schooling."
101 Mary Arends-Kuenning, “The equity and efficiency of doorstep delivery of contraceptives in Bangladesh."

102 Sajeda Amin, Ian Diamond, Ruchira T. Naved, and Margaret Newby, "Transition to adulthood of female factory workers: Some evidence from Bangladesh."

*103 Margaret E. Greene and Ann E. Biddlecom, "Absent and problematic men: Demographic accounts of male reproductive roles."

104 Michael P. Todaro, "Urbanization, unemployment, and migration in Africa: Theory and policy."

105 Geoffrey McNicoll, "Population and poverty: A review and restatement."
106 Sajeda Amin and Gilda Sedgh, "Incentive schemes for school attendance in rural Bangladesh."

107 Martin Brockerhoff and Paul Hewett, "Ethnicity and child mortality in subSaharan Africa."

108 Ann E. Biddlecom and Bolaji M. Fapohunda, "Covert contraceptive use: Prevalence, motivations, and consequences."

109 John Bongaarts and Griffith Feeney, "On the quantum and tempo of fertility."
110 Barbara S. Mensch, Daniel Bagah, Wesley H. Clark, and Fred Binka, "The changing social environment for adolescents in the Kassena-Nankana District of northern Ghana: Implications for reproductive behavior."

111 Martin Brockerhoff and Ann Biddlecom, "Migration, sexual behavior, and HIV diffusion in Kenya."

112 Zeba A. Sathar and John B. Casterline, "The onset of fertility transition in Pakistan." 